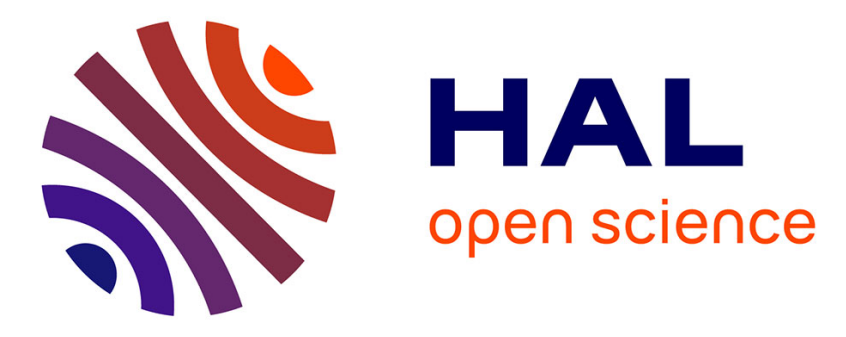

\title{
New architecture of MEMS microphone for enhanced performances
}

Jaroslaw Czarny, Arnaud Walther, B. Desloges, Philippe Robert, Emmanuel Redon, Thierry Verdot, Kerem Ege, Cécile Guianvarc'H, Jean-Louis Guyader

\section{- To cite this version:}

Jaroslaw Czarny, Arnaud Walther, B. Desloges, Philippe Robert, Emmanuel Redon, et al.. New architecture of MEMS microphone for enhanced performances. 2013 International Semiconductor Conference Dresden-Grenoble, ISCDG 2013, Sep 2013, Dresden, Germany. pp.1-4, 10.1109/ISCDG.2013.6656312 . hal-00903737

\section{HAL Id: hal-00903737 https://hal.science/hal-00903737}

Submitted on 18 Feb 2021

HAL is a multi-disciplinary open access archive for the deposit and dissemination of scientific research documents, whether they are published or not. The documents may come from teaching and research institutions in France or abroad, or from public or private research centers.
L'archive ouverte pluridisciplinaire HAL, est destinée au dépôt et à la diffusion de documents scientifiques de niveau recherche, publiés ou non, émanant des établissements d'enseignement et de recherche français ou étrangers, des laboratoires publics ou privés. 


\section{New architecture of MEMS microphone for enhanced performances}

\author{
J. Czarny, A. Walther, B. Desloges, Ph. Robert \\ MEMS Sensors Laboratory \\ CEA, LETI \\ Grenoble, France \\ jaroslaw.czarny@cea.fr
}

\author{
E. Redon, T. Verdot, K. Ege, C. Guianvarc'h, \\ J. L. Guyader \\ LVA-Insa Lyon \\ Villeurbanne, France
}

\begin{abstract}
This paper describes the conception, designs consideration and fabrication process of a novel MEMS microphone. The presented microphone not only uses a new architecture, the sensitive part being beams moving within the plane of the substrate, but also uses an innovative detection means with Silicon piezo-resistive nanogauges. Modelization will consider acoustic and mechanical interactions. Besides, at MEMS scale, accurate simulation of the sensor must take into account thermal and viscous boundary layers in acoustics, and we will show that the presented sensor takes benefit from these short scale effects, which leads to achieve theoretical resolution as low as $24 \mathrm{~dB}$.
\end{abstract}

Keywords-MEMS; microphone; sensor; acoustic; multiphysics simulations

\section{INTRODUCTION}

Constant development of MEMS microphones enabled one to fabricate devices with characteristics comparable to classical electret microphones. Besides the similarities in size and performance, MEMS microphones provide possibility of digital output and compatibility with Surface-Mount Technology (SMT), maintaining at the same time lower unit price. Therefore they increasingly replace electret microphones in modern applications.

Most of the commercial and state of the art reports concern capacitive microphones [1-4]. Furthermore piezo-resistive [5,6] and piezoelectric [7-9] microphones, being a minority, are not commercially available for consumer applications. CEA-LETI develops piezo-resistive microphone basing on socalled M\&NEMS technological platform in order to integrate various sensors on one silicon die [10]. This technology, which uses suspended Silicon piezo-resistive nanogauges as detection means, has already been applied to inertial sensors and has shown to be promising for size reduction or performance improvement of such sensors.

\section{PRINCIPLE OF OPERATION}

Presented microphone (Fig. 1) consists of 4 rigid micro beams placed between the inlet vents that guide the sound waves and outlet vents that enable pressure equilibration in a back cavity. Micro-slits between the beams and top and bottom wafers enable the motion of the beams while ensuring pressure drop from one to the other side of the beam. Stress induced by the motion of a beam inside suspended piezo-resistive $\mathrm{Si}$ gauges is transduced into resistance variations and measured by use of Wheatstone bridge architecture.

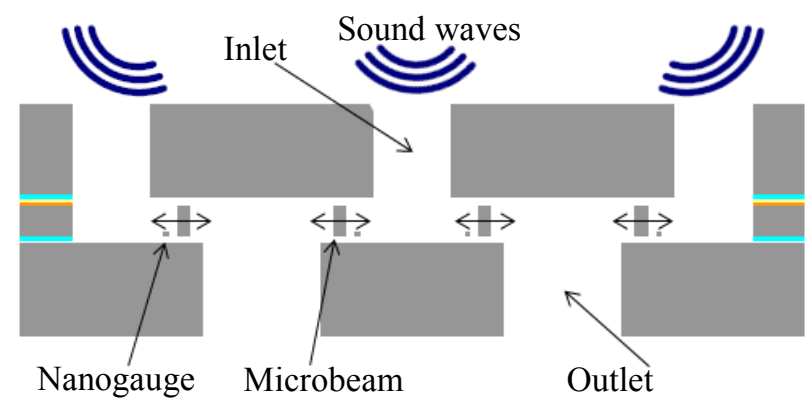

Fig. 1. Cross-sectional scheme of the microphone with acoustic configuration and sensing elements

One side of each beam is clamped by use of micro-hinge while the other one is free (Fig. 2).

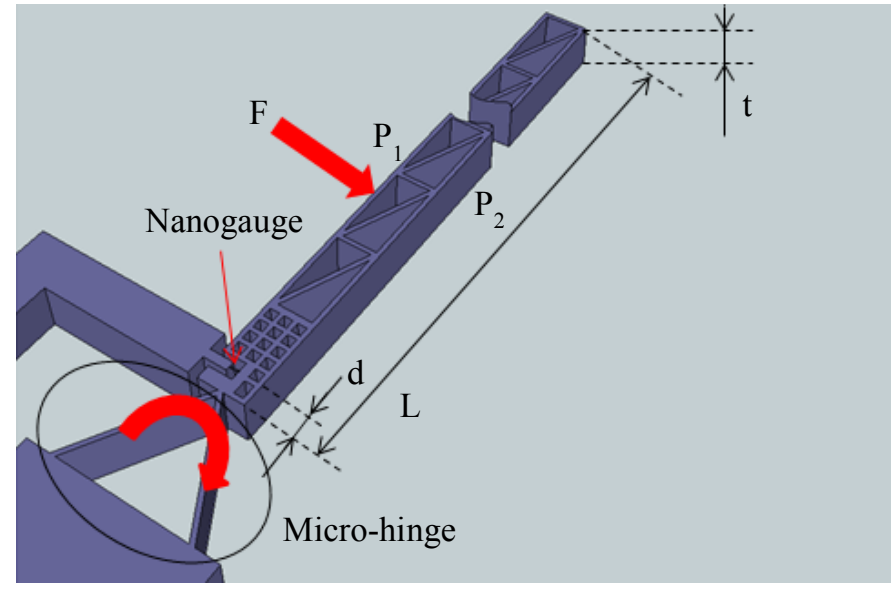

Fig. 2. Principle of detection in M\&NEMS microphone.

Force acting on the beam can be expressed as:

$$
F=\left(P_{1}-P_{2}\right) t L
$$


And force exerted on the gauge as:

$$
F_{g}=\gamma_{M} F \frac{L}{2 d}
$$

Where $\gamma_{M}$ is a mechanical correction factor [11].

Finally the variation of gauge resistance is:

$$
\Delta R=\Pi R \frac{\gamma_{M} F L}{S_{g} 2 d}
$$

Where $\Pi, \mathrm{R}$ and $\mathrm{S}_{\mathrm{g}}$ are piezoresitive coefficient, nominal resistance of a nanogauge and cross-section area of a nanogauge respectively.

Given that the resistance variation depends strongly on the force generated in strain gauges, we have revealed essential amplification mechanisms that should be optimized. First action was to improve lever effect by increasing the ratio between distances $\mathrm{L}$ and $\mathrm{d}$, secondly the cross-section $\mathrm{S}_{\mathrm{g}}$ of strain gauges was reduced.

The gauges are arranged into full Wheatstone bridge in such manner that, on the occurrence of sound pressure, two gauges will be compressed while the other two will be stretched. Such sensor architecture ensures self-cancelation of random accelerations.

\section{DESIGN CONSIDERATION}

Optimization of the presented microphone has been done in two main steps. We have analyzed the transduction chain in order to reveal the main sources of electro-mechanical noise, afterwards COMSOL simulations were used to establish proper dimensions of acoustic network.

\section{A. Electro-mechanical noises}

Main noises of the microphone based on the piezo-resistive detection are: Brownian noise acting on a micro-mechanisms, Johnson and Flicker noise acting on nanogauges and Electronic noise acting on a readout electronics (Fig. 3).

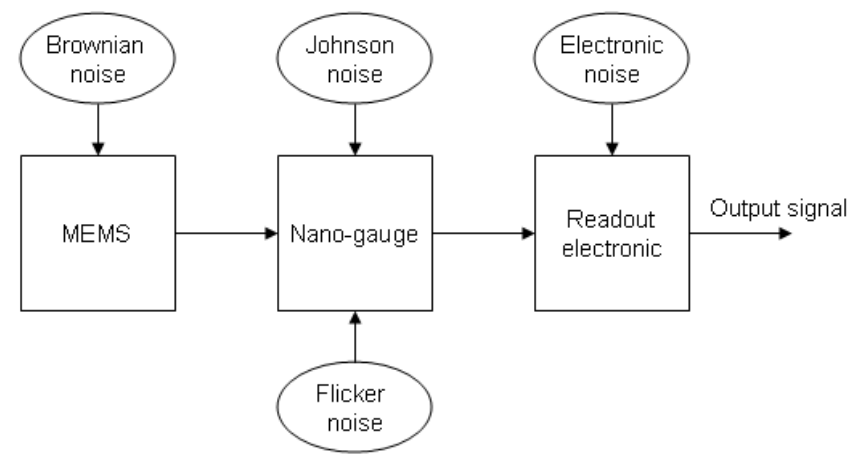

Fig. 3. Electro-mechanical noises in transduction chain.

Analysis of noise contribution over the sensor bandwidth (Fig. 4) showed that Flicker noise and Johnson noise are the main noises which limit the performance at lower and higher frequencies respectively. Both of these noises have origins in electrical specification of strain gauges, in order to reduce them we have optimized gauge dimensions and doping level.

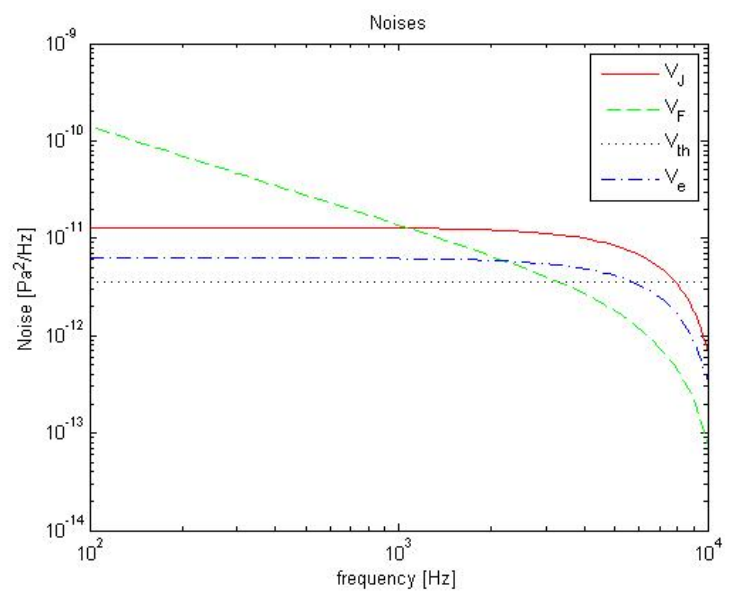

Fig. 4. Characteristic of noises over frequency, where $V_{J}-$ Johnson noise, $\mathrm{V}_{\mathrm{F}}-$ Flicker noise, $\mathrm{V}_{\mathrm{th}}-$ Brownian noise, $\mathrm{V}_{\mathrm{e}}-$ Electronic noise.

\section{B. Acoustic simulations}

Classical acoustic simulation tools dedicated for large cavities problems are not relevant at the scale of the MEMS (Fig. 5). Dimensions of designed microphone - ranging from few $100 \mu \mathrm{m}$ down to $1 \mu \mathrm{m}$ - are smaller than the thicknesses of thermal and viscous boundary layers for the frequency range of interest $(70 \mathrm{~Hz}$ to $10 \mathrm{kHz}) \quad[12]$. In consequence, viscothermal acoustic model has to be considered for the acoustic simulations.

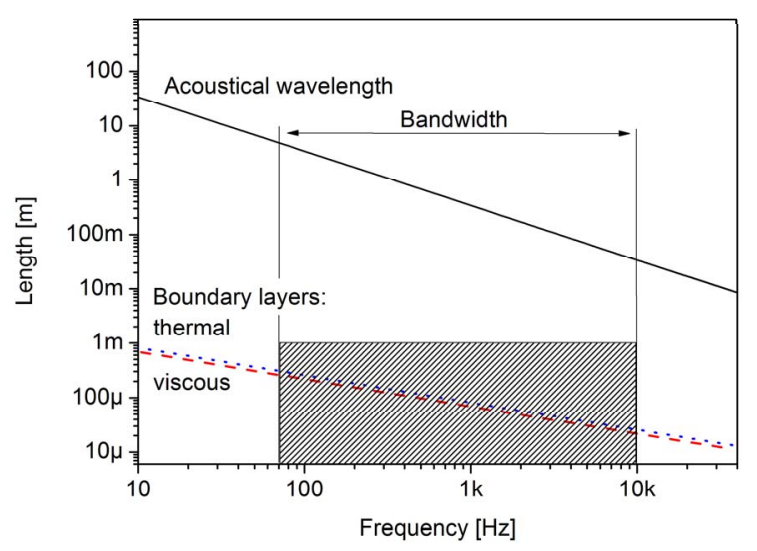

Fig. 5. Acoustic wavelength and thickness of thermal and viscous boundary layers as a function of a frequency. Hatched rectangle indicates the dimensions of CEA-LETI sensor.

2D and 3D models of a microphone were prepared under COMSOL thermoacoustic module. Conditions of simulations are presented on Fig. 6: pressure fluctuation of $1 \mathrm{~Pa}$ was set on the entrance of the sensor. To simulate a bottom-port package configuration [13], $0 \mathrm{~Pa}$ boundary conditions were set at the outlet vent. In order to simplify the model only one beam has been taken into account. 


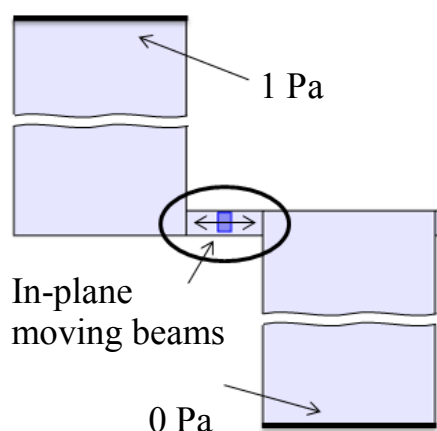

Fig. 6. 2D view on FEM model (cross-section of MEMS); encircled part is showed on Fig. 7.

Initially the pressure across all of the MEMS cavities has been set to $0 \mathrm{~Pa}$. Pressure of $1 \mathrm{~Pa}$ that occurs at the inlet of a sensor distributes across the inlet vent and interact with the microbeam (Fig. 7). Due to thermal and viscous phenomena's the micro slits $(1-2 \mu \mathrm{m})$ situated below and above the beam create a seal resulting in significant drop of pressure over the beam.

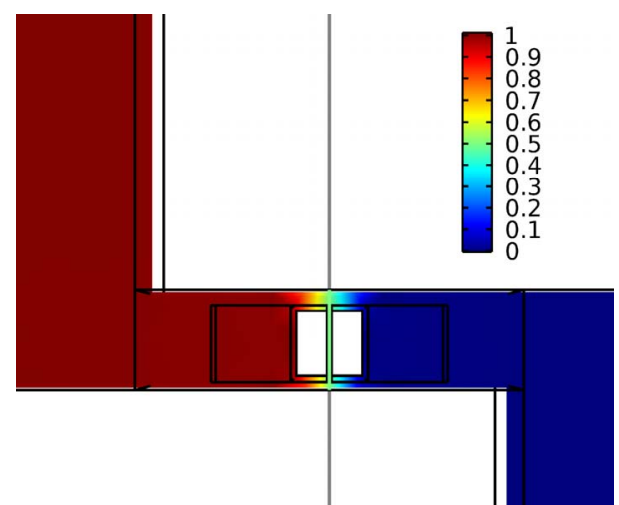

Fig. 7. Pressure distribution $[\mathrm{Pa}]$. in thermoacoustic 3D model (frequency $1 \mathrm{kHz}$ )

By coupling mechanical properties of a beam with sound pressure propagation, we have computed the vibroacoustic response of the sensor over the bandwidth for $2 \mathrm{D}$ and $3 \mathrm{D}$. The amplitude of the beam displacement is derived and plotted in (Fig. 8): pressure sensitivity of the MEMS device is proportional to this transfer function.

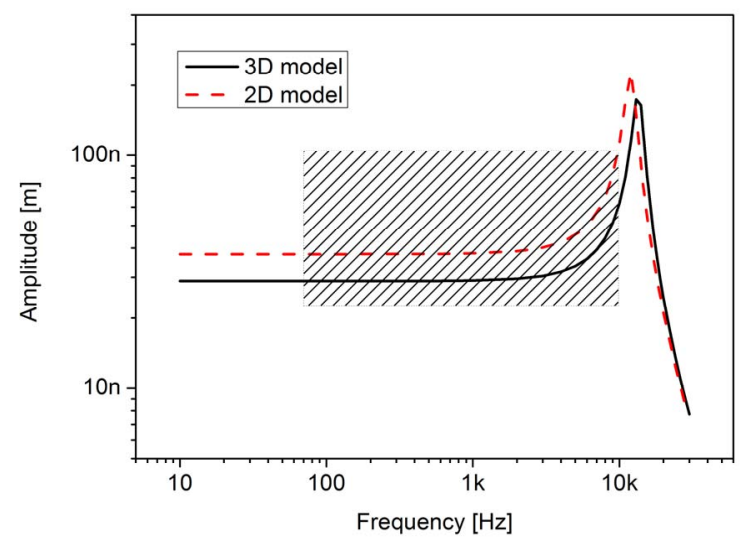

Fig. 8. Amplitude of average beam displacement over the bandwidth with hatched rectangle showing sensor bandwidth.
Described model enabled us to optimize dimensions of each acoustic cavity in the microphone as a function of beam displacement. While the dimensions of inlet and outlet vents have marginal impact on the amplitude of beam displacement, the micro-slits dimensions have to be kept as small as possible.

\section{Expected performance}

Coupling of analytical and numerical considerations enabled us to evaluate the expected sensitivity $-4.8 \mathrm{mV} / \mathrm{Pa} @ 1 \mathrm{kHz}$ and resolution $-24 \mathrm{~dB}$. Those values are valid for a bandwidth of $10 \mathrm{kHz}$ and current consumption of $200 \mu \mathrm{A}$.

\section{TECHNOLOGICAL PROCESS}

The MEMS fabrication is carried out in clean room with typical micro-electronic process and starts with SOI substrate with $1 \mu \mathrm{m}$ buried oxide and $0.25 \mu \mathrm{m}$ Si top layer. Nanogauges of $0.25 \mu \mathrm{m}$ width are defined by DUV lithography and etched by RIE. Then a $1 \mu \mathrm{m}$ thick oxide is deposited in order to protect the gauges. Afterwards, $10 \mu \mathrm{m}$ thick mono-crystalline Silicon is grown by epitaxy and MEMS structure is defined by DRIE. A cap with contact redistribution layer is bonded on top of the first wafer with eutectic bonding. Handle and cap wafers are then thinned and etched with DRIE in order to open top and bottom vents. The mechanical structure is eventually released with vapour HF etching. A side view of the stack is shown on Fig. 9.

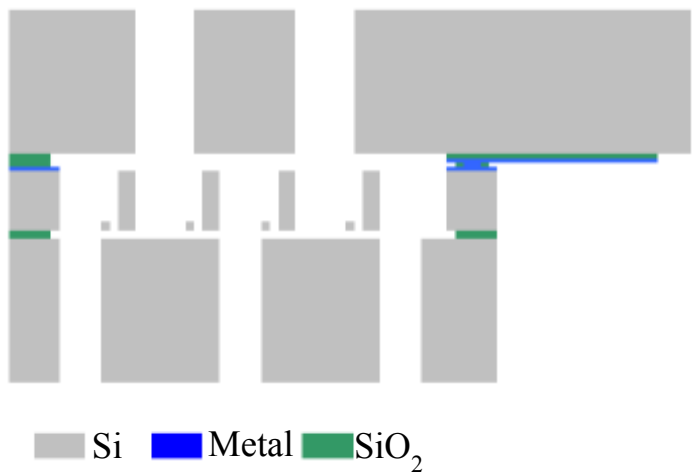

Fig. 9. Side view of a fabrication process

Described fabrication process is carried out at CEA-LETI, most crucial technological steps including nanogauges definition and MEMS etching have been already realized. Final shape of MEMS part with zoom on nanogauge and rectangles indicating top (blue) and bottom (green) cavities is shown on Fig. 10. 


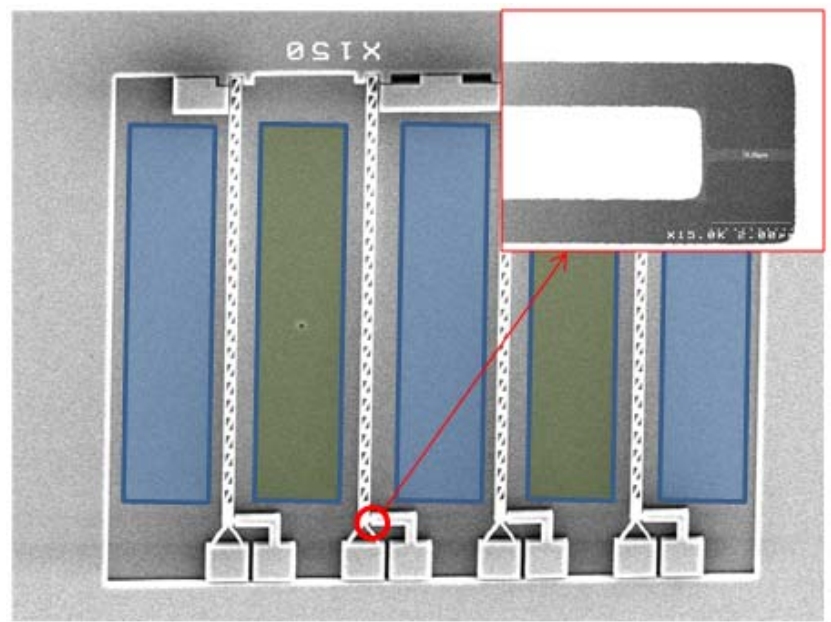

Fig. 10. Top view of the micro-beams and the nanogauge.

\section{ACKNOWLEDGMENT}

This work is supported by the Agence Nationale de la Recherche (ANR) as part of the MADNEMS project (ANR11-NANO-026).

\section{REFERENCES}

[1] Y. Iguci, M. Goto, M. Iwaki, A. Ando, K. Tanioka, T. Tajima, F. Takeshi; S. Matsunaga, and A. Yasuno, "Silicon microphone with wide frequency range and high linearity," Sensors and Actuators A, vol. 135, pp. 420-425, 2007.

[2] H. S. Kwon and K. C. Lee, "Double-chip condenser microphone for rigid backplate using DRIE and wafer bonding technology," Sensors and Actuators A, vol. 138, pp. 81-86, 2007.

[3] A. Torkkeli, O. Rusanen, J. Saarilahti, H. Seppä, H. Sipola, and J. Hietanen, "Capacitive microphone with low-stress polysilicon membrane and high-stress polysilicon backplate," Sensors and Actuators A, vol. 85, pp. 116-123, 2000.

[4] J. W. Weigold, T. J. Brosnihan, J. Bergeron, and X. Zhang, "A MEMS condenser microphone for consumer applications," 19th IEEE International Conference on Micro Electro Mechanical Systems, Istambul, pp. 86-89, Jan 2006.

[5] R. Dieme, "Characterization of noise in MEMS piezoresistive microphones," MSc Thesis dissertation, University of Florida, 2006.

[6] M. Papila, R. T. Haftka, T. Nishida, and M. Sheplak, "Piezoresistive microphone design pareto optimization: tradeoff between sensitivity and noise floor," Journal of Microelectromechanical Systems, vol. 15, no. 6, pp. 1632-1643, 2006.

[7] R. J. Littrell, "High performance piezoelectric MEMS microphones," $\mathrm{PhD}$ Thesis dissertation, University of Michigan, 2010.

[8] E. S. Kim, "Piezoelectric MEMS for audio signal transduction, microfluidic management, resonant mass sensing, and movable surface micromachined structures," IEEE International Ultrasonics Symposium Proceedings, pp. 924-929, Nov 2008.

[9] W. S. Lee and S. S. Lee, "Piezoelectric microphone built on circular diaphragm," Sensors and Actuators A, vol. 144, pp. 367-373, 2008.

[10] P. Robert, P. Rey, A. Berthelot, G. Jourdan, Y. Deimerly, S. Louwers, J. Bon, F. X. Boillot, and J. Collet, "M\&NEMS: a technological platform for 10-axis sensor," SSI Conference, Amsterdam, March 2013.

[11] T. Verdot, C. Guianvarch, J. Czarny, E. Redon, K. Ege, and J.-L. Guyader, "Modélisation d'une architecture innovante de microphone MEMS à détection par nano jauges" Proceedings of the XXIe Congrès Français de Mécanique, CFM2013, Bordeaux, August 2013

[12] N. Joly, "Finite Element Modeling of Thermoviscous Acoustics on Adapted Anisotropic Meshes: Implementation of the Particle Velocity and Temperature Variation Formulation," Acta Acousticaunited with Acoustica, vol. 96, pp. 102-114, 2010.

[13] C. Guianvarch, T. Verdot, J. Czarny, E. Redon, K. Ege J.-L. Guyader, A. Walther and P. Robert, "New planar nano-gauge detection microphone: Analytical and numerical acoustic modeling", Proceedings of $21 \mathrm{st}$ International Congress on Acoustics, ICA 2013, Montreal, june 2013 